Article

\title{
Immunoreactivity of Muscarinic Acetylcholine M2 and Serotonin 5-HT2B Receptors, Norepinephrine Transporter and Kir Channels in a Model of Epilepsy
}

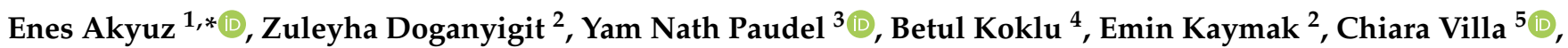

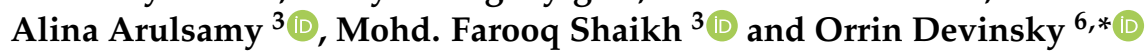 \\ 1 Department of Biophysics, Faculty of International Medicine, University of Health Sciences, \\ Istanbul 34668, Turkey \\ 2 Department of Histology and Embryology, Faculty of Medicine, Yozgat Bozok University, \\ Yozgat 66100, Turkey; zuleyha.doganyigit@yobu.edu.tr (Z.D.); emin.kaymak@yobu.edu.tr (E.K.) \\ 3 Neuropharmacology Research Strength, Jeffrey Cheah School of Medicine and Health Sciences, \\ Monash University Malaysia, Bandar Sunway 47500, Selangor, Malaysia; yam.paudel@monash.edu (Y.N.P.); \\ alina.arulsamy@monash.edu (A.A.); farooq.shaikh@monash.edu (M.F.S.) \\ 4 Faculty of Medicine, Yozgat Bozok University, Yozgat 66100, Turkey; betulkoklu24@gmail.com \\ 5 School of Medicine and Surgery, University of Milano-Bicocca, 20900 Monza, Italy; chiara.villa@unimib.it \\ 6 Comprehensive Epilepsy Center, Department of Neurology, NYU Langone School of Medicine, \\ New York, NY 10010, USA \\ check for \\ updates \\ * Correspondence: enesakyuz25@gmail.com (E.A.); od4@nyu.edu (O.D.); Tel.: +90-535-7629979 (E.A.); \\ +1-646-558-0803 (O.D.)
}

Citation: Akyuz, E.; Doganyigit, Z.; Paudel, Y.N.; Koklu, B.; Kaymak, E.; Villa, C.; Arulsamy, A.; Shaikh, M..F.; Devinsky, O. Immunoreactivity of Muscarinic Acetylcholine M2 and Serotonin 5-HT2B Receptors,

Norepinephrine Transporter and Kir Channels in a Model of Epilepsy. Life 2021, 11, 276. https://doi.org/ $10.3390 /$ life 11040276

Academic Editor:

Hieronim Jakubowski

Received: 22 February 2021

Accepted: 23 March 2021

Published: 26 March 2021

Publisher's Note: MDPI stays neutral with regard to jurisdictional claims in published maps and institutional affiliations.

Copyright: () 2021 by the authors. Licensee MDPI, Basel, Switzerland. This article is an open access article distributed under the terms and conditions of the Creative Commons Attribution (CC BY) license (https:// creativecommons.org/licenses/by/ $4.0 /)$.
Abstract: Epilepsy is characterized by an imbalance in neurotransmitter activity; an increased excitatory to an inhibitory activity. Acetylcholine (ACh), serotonin, and norepinephrine (NE) may modulate neural activity via several mechanisms, mainly through its receptors/transporter activity and alterations in the extracellular potassium $\left(\mathrm{K}^{+}\right)$concentration via $\mathrm{K}^{+}$ion channels. Seizures may disrupt the regulation of inwardly rectifying $\mathrm{K}^{+}(\mathrm{Kir})$ channels and alter the receptor/transporter activity. However, there are limited data present on the immunoreactivity pattern of these neurotransmitter receptors/transporters and $\mathrm{K}^{+}$channels in chronic models of epilepsy, which therefore was the aim of this study. Changes in the immunoreactivity of epileptogenesis-related neurotransmitter receptors/transporters (M2, 5-HT2B, and NE transporter) as well as Kir channels (Kir3.1 and Kir6.2) were determined in the cortex, hippocampus and medulla of adult Wistar rats by utilizing a Pentylenetetrazol (PTZ)-kindling chronic epilepsy model. Increased immunoreactivity of the NE transporter, M2, and 5-HT2B receptors was witnessed in the cortex and medulla. While the immunoreactivity of the 5-HT2B receptor was found increased in the cortex and medulla, it was decreased in the hippocampus, with no changes observed in the M2 receptor in this region. Kir3.1 and Kir6.2 staining showed increase immunoreactivity in the cerebral cortex, but channel contrasting findings in the hippocampus and medulla. Our results suggest that seizure kindling may result in significant changes in the neurotransmitter system which may contribute or propagate to future epileptogenesis, brain damage and potentially towards sudden unexpected death in epilepsy (SUDEP). Further studies on the pathogenic role of these changes in neurotransmitter receptors/transporters and $\mathrm{K}^{+}$channel immunoreactivity may identify newer possible targets to treat seizures or prevent epilepsy-related comorbidities.

Keywords: PTZ; chronic epilepsy; M2; norepinephrine; 5-HT2B

\section{Introduction}

Epilepsy is a debilitating disease as well as a global health concern, affecting nearly 70 million people worldwide [1]. Although there are many anti-seizure medications (ASMs) 
available in the current market [2] that may provide symptomatic relief for epileptic patients, about $30 \%$ of these patients still have little to no control of their devastating epileptic seizure condition [3]. Despite the rapid scientific advances in understanding the molecular biology, pathology, genetics and neurophysiology of epilepsy [4], efficient treatment strategies for drug-resistant epilepsy and prevention interventions for epilepsy-related comorbidities remain unsolved [5]. Since epilepsy results from an imbalance between the excitatory and inhibitory neurotransmitters, a deeper understanding of the neurotransmission mechanisms in epilepsy may suggest newer and more effective approaches to prevent or treat epilepsy and its associated comorbidities, as well as other neuropsychiatric disorders such as autism and schizophrenia, which all share similar imbalances in the excitatory/inhibitory ratio [6].

While glutamate and gamma-aminobutyric acid (GABA) are the main neurotransmitters governing neuronal excitability and inhibition in epilepsy, other neurotransmitters such as serotonin (5-HT), norepinephrine (NE) and acetylcholine (ACh), which also play important roles in neuronal transmission, should not be dismissed. Glutamatergic and gamma-aminobutyric acid (GABA)-ergic systems comprise a cell-to-cell specific modulatory system, while 5-HT, NE, and ACh comprise a more general (affecting general neuronal populations) modulatory system, where both modulatory systems have been implicated in modulating seizure thresholds and epilepsy pathogenesis [7,8]. Interestingly, different neurotransmission pathway dysfunctions may contribute to different epilepsy pathologies [9]. For example, the dopamine-norepinephrine-epinephrine cycle may activate the hormonal and neural pathways of excitatory and inhibitory seizure effects [10], while the serotonergic pathways may modulate the cortical tone via postsynaptic and presynaptic receptors, which may influence emotion, cognition, and motor functions directly and indirectly (e.g., ACh release) [11]. In addition, neurotransmitter receptors may also play a key role in epilepsy pathology. The antagonist of the serotonin receptor, $5 \mathrm{HT}-2 \mathrm{~B} / 2 \mathrm{C}$, managed to increase the seizure threshold in a mouse electroshock model and protected against Pentylenetetrazol (PTZ)-induced tonic/myoclonic seizures [12]. However, in a retrospective case series, the selective 5-HT2C agonist lorcaserin suppressed motor seizures in children and young adults with treatment-resistant epilepsy [13]. These contrasting effects of the serotonin receptor suggest that downstream activity such as ion channels may have a more crucial role in epilepsy than just the neurotransmitter receptor activation/inhibition.

Neurotransmitters regulate ion channel activities, including the inwardly rectifying $\mathrm{K}^{+}$ channels (Kir), an ion channel that is often associated with the epilepsy pathology $[14,15]$. For example, the Kir3.1 channel is activated at the muscarinic Ach receptor-2 (M2) [16] by the ACh neurotransmitter, which has been shown to maintain resting membrane potential (RMP) and reduce cellular excitability [17]. Kir3 channels and M2 receptors are also candidates for autonomic dysfunctions accompanying epilepsy leading to detrimental epilepsy comorbidities [18]. Adenosine triphosphate (ATP) sensitive $\mathrm{K}^{+}\left(\mathrm{K}_{\mathrm{ATP}}\right)$ channels (Kir6), on the other hand, are normally found closed and may protect against hypoxia and ischemia conditions in the hippocampus and cortex [19], but may also regulate neuronal excitability and spontaneous neuronal firing in the striatum of epileptic conditions [20]. These latter two studies indicate that the location/area of this neurotransmission and ion channel activation in the brain may result in varying neuronal outcomes and, thus, may also exhibit varied pathology/immunoreactivity in an epilepsy model. For instance, seizures arising in the temporal-limbic regions alter brainstem centres that control cardiac and respiratory functions [21], while temporal lobe epilepsy (TLE) may cause neuronal degeneration and abnormal neurogenesis that may lead to chronically increased hippocampal associated functional loss [22]. Furthermore, knowledge regarding whether the seizures or the changes in the immunoreactivity and activity of these receptors and ion channels appear first in epilepsy conditions remains undetermined.

Therefore, in the present study, we aimed to investigate the immunoreactivity changes of neurotransmitter receptors; M2, 5-HT2B receptors, NE transporters, and ion channels; Kir3.1 and Kir6.2, in the cortex, hippocampus, and medulla in a PTZ kindling rodent model 
of chronic epilepsy. The findings from this study will hopefully aid in elucidating a clearer epileptogenesis pathway via the neurotransmitter systems, especially in the chronic stages, thus advancing targeted-intervention studies for epilepsy.

\section{Materials and Methods}

Wistar albino male rats (280-380 g, $n=20)$ were obtained from Kayseri Erciyes University's Research Center. Animals were housed in a controlled environment with a temperature of $24 \pm 2{ }^{\circ} \mathrm{C}$ and humidity of $60 \%$ under a 12-h light/dark cycle. They were given free access to water and food ad libitum. All procedures were performed within the recommendations of the Guide for the Care and Use of Laboratory Animals adopted by the National Institutes of Health (NIH, Bethesda, MD, USA) and the Helsinki Declaration. The experimental protocols for this study were approved by the Animal Ethics Committee of the Kayseri Erciyes University (numbered: 19/027). All efforts were made to minimize animal suffering during each procedure. Animals were acclimatised to the room prior to any experimentation to avoid distress.

\subsection{PTZ-Kindling Epilepsy Model}

Epilepsy was induced in the animals through PTZ-kindling (generalized tonic-clonic seizures). First, the PTZ solution was prepared by dissolving PTZ (P6500, Sigma-Aldrich, St. Louis, $\mathrm{MO}, \mathrm{USA})$ in an isotonic saline $(0.9 \% \mathrm{NaCl})$. Rats were randomly divided into two groups; Group $1(n=10)$, which is a control group that only received intraperitoneal (i.p.) injection of $0.9 \%$ saline, and Group $2(n=10)$, which is a PTZ-kindling group that received i.p. injection of $35 \mathrm{mg} / \mathrm{kg}$ of PTZ solution. The PTZ-kindling epilepsy model in this study was induced based on an already established protocol [23]. Briefly, animals in Group 2 were intraperitoneally injected with a sub-convulsive dose of PTZ $(35 \mathrm{mg} / \mathrm{kg})$ three times a week, on alternate weekdays. PTZ injection was continued until seizure kindling was achieved, but never longer than 4 weeks. Seizure kindling was considered achieved when the animals showed a Score 4 or 5 after three consecutive injections of PTZ [24].

A month after kindling, the final dose for PTZ susceptibility was performed with a single PTZ injection ( $50 \mathrm{mg} / \mathrm{kg}$, i.p.). The seizure reaction after the $50 \mathrm{mg} / \mathrm{kg}$ PTZ was

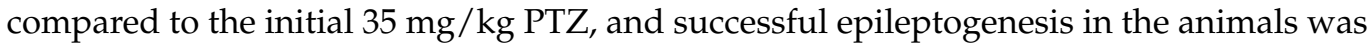
considered achieved when there was a significant enhancement in the reaction [25]. After each injection (PTZ/saline), the rats from both groups were each placed individually in a transparent Plexiglas cage and their convulsive behaviour was independently monitored for $30 \mathrm{~min}$. The seizure severity, the latency of seizure onset, and the seizure duration of each animal were measured and analysed by a blinded experimenter. The seizure severity was scored using the commonly utilized Racine's classification system:

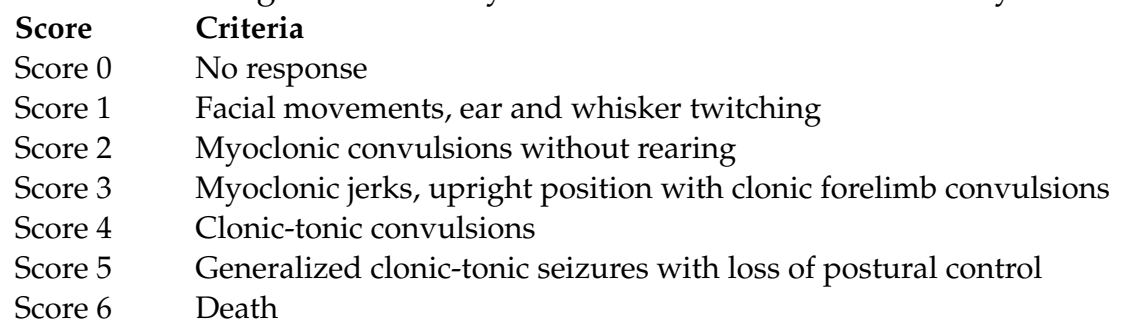

After the final seizure measurements were recorded, the animals were anesthetized with ketamine/xylazine (90/10 mg/kg, i.p.) and were sacrificed humanely. The brains of the animals were extracted for immunohistochemistry analysis (Figure 1). 


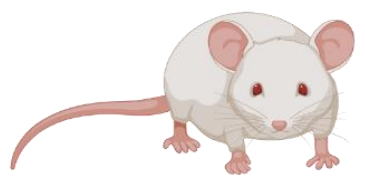

Wistar albino rats
PTZ injection (35 mg/kg, i.p.)

\section{3 times a week}

\section{Day 1}

Day 28

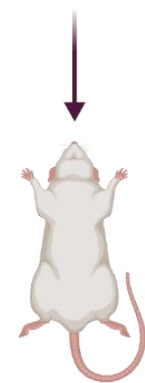

Tissue removal by dissection

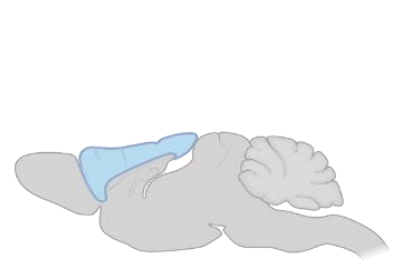

Cortex

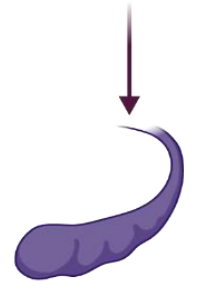

Hippocampus

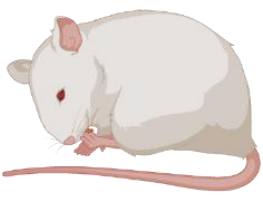

PTZ-kindled rats

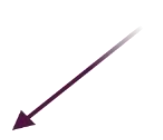

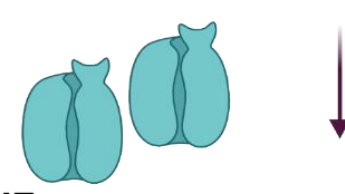

NE transporters

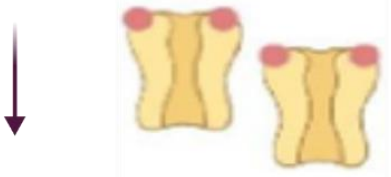

Serotonin receptors

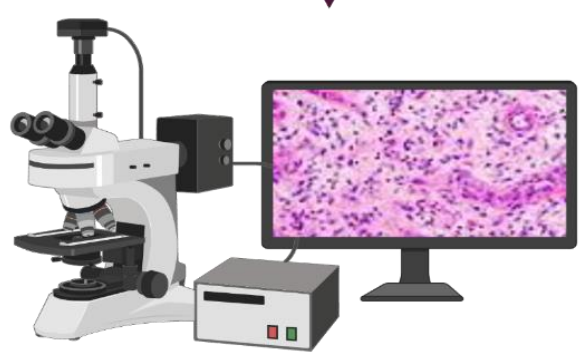

Histopathology analysis

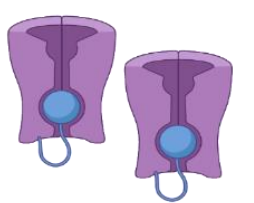

Kir3.1 channels

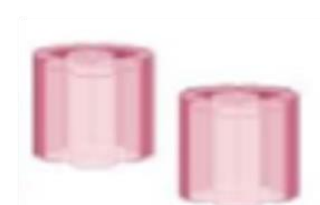

Kir6.2 channels

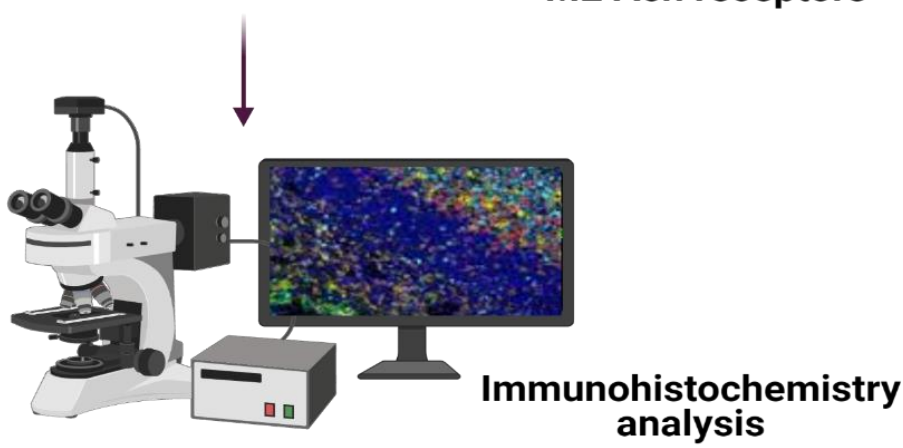

M2 Ach receptors

Figure 1. Pictorial representation depicting the current experiment. This figure was created with BioRender.com (accessed on 7 March 2021). Ach, Acetylcholine; Kir, inwardly rectifying $\mathrm{K}^{+}$; NE, norepinephrine; PTZ, Pentylenetetrazol

\subsection{Histological and Pathological Staining}

Immunohistochemistry (IHC) staining (Figure 1) was performed as per the methodology described in the previous literature [26]. The cerebral cortex, hippocampus, and medulla tissues were dissected and immediately fixed with $4 \%$ formaldehyde solution. Then, the tis- 
sues were embedded in paraffin blocks before 5-6 $\mu \mathrm{m}$ sections of each tissue were obtained via a microtome. These sections were placed on glass slides. When ready to use, the slides were placed in an alcohol solution of ascending concentration gradient $(70,80$, and 90\%), each for $5 \mathrm{~min}$. Then, the slides were placed in a 100\% alcohol solution for $5 \mathrm{~min}$ and then in xylene solution for 1 min (twice). Next, Haematoxylin and Eosin (H\&E) staining was performed on the tissue sections before proceeding towards visualization. The gross histopathological changes (e.g., necrosis or haemorrhage) of the tissue were evaluated under Olympus BX51 model microscope.

As for the immunoreactivity of the M2 and 5-HT2B receptor as well as the NE transporter in the cerebral cortex, hippocampus, and medulla, this was determined using the avidin-biotin-peroxidase IHC methodology. Similarly, the 5-6 $\mu \mathrm{m}$ sections were kept on slides at $60{ }^{\circ} \mathrm{C}$ overnight. They were then deparaffinized and rehydrated by passing them through xylene and through graded alcohol series (100\%, 95\%, and 70\%). Next, the slides were washed three times for 5 min with phosphate buffer solution (PBS). The antigen retrieval step was performed by boiling the tissue sections 5 times, 3 min each at $600 \mathrm{~W}$ in a microwave oven with $5 \%$ citrate buffer. The slides were then kept in the same buffer solution for $20 \mathrm{~min}$. Next, the sections were washed with PBS and were treated with 3\% hydrogen peroxide $\left(\mathrm{H}_{2} \mathrm{O}_{2}\right)$ for $5 \mathrm{~min}$ to prevent endogenous peroxidase activity. Any non-specific binding was blocked with normal horse serum at room temperature for $20 \mathrm{~min}$ and washed with PBS. Primary antibodies against Kir3.1 (mouse monoclonal, 1:200, Alomone Labs, Jerusalem, Israel (APC-005)), Kir6.2 (rabbit polyclonal, 1:200, Alomone Labs, Jerusalem, Israel (APC-020)), muscarinic acetylcholine receptor M2, mAChR (rabbit polyclonal, 1:200, Alomone Labs, Jerusalem, Israel (APC-002)), norepinephrine transporter (rabbit polyclonal, 1:200, Alomone Labs, Jerusalem, Israel (AMT-002)) and serotonin receptor 2B (rabbit polyclonal, 1:200, Alomone Labs, Jerusalem, Israel (ASR-035)) were diluted in PBS and incubated with the slides at $4{ }^{\circ} \mathrm{C}$. As a negative control, PBS was used instead of the primary antibodies. After washing, the sections were incubated with biotin secondary antibody for $30 \mathrm{~min}$, and then washed again. The sections were then treated with the Avidin-Biotin (AB) enzyme reagent for $30 \mathrm{~min}$ and were washed with the peroxidase substrate, diaminobenzidine (DAB), for $5 \mathrm{~min}$. To stop the DAB reaction, the slides were washed with deionized $\mathrm{H}_{2} \mathrm{O}$ for $5 \mathrm{~min}$. The sections were contrast stained with Gill haematoxylin and were washed several times with deionized $\mathrm{H}_{2} \mathrm{O}$. Finally, the tissue sections were dehydrated with increasing alcohol series and passed through xylene before covering with Entellan mounting medium and cover slipped. Images were obtained with a DP71 digital camera under the Olympus BX51 model light microscope and the tissue sections were evaluated in terms of immunoreactivity differences with the Image-J software. The interpretation of the data was evaluated depending on the intensity of the staining compared to the control. A significant change in staining intensity in a region was accepted as an indicator of the activity of the related region in terms of the relevant neurotransmitter content.

\subsection{Statistical Analysis}

The SPSS program (SPSS for Windows, SPSS Inc., Chicago, IL, USA, version 24.0) was used to perform statistical analysis on the behavioural and histology results. Data are given as mean values \pm standard error of the mean (SEM). An inter-group comparison of the results was analysed with the one-way ANOVA test, while the independent sample T-test was used for binary comparisons of the results. Differences were considered significant at * $p<0.05,{ }^{* *} p<0.01$ and ${ }^{* * *} p<0.001$.

\section{Results}

\subsection{Racine-Scoring of PTZ-Kindling Model in Animals}

After the 13th PTZ injection, all Group 2 rats (100\%) displayed chronic epilepsylike behaviour with generalized tonic-clonic seizures (Score 5) (Figure 2, ${ }^{* * *} p<0.001$ ). The mean seizure latency of all injections in Group 2 was $5.31 \pm 0.58$, and their mean seizure duration was $308 \pm 95$ s. No seizure activity was observed in the control animals 
(Group 1). There were also no observable significant differences in body weight either in the control (307.41 \pm 8.98 vs. $314.11 \pm 8.47, p>0.05$, Figure $3 \mathrm{~A}$ ) or PTZ-kindled epilepsy groups (308.12 \pm 8.58 vs. $328.24 \pm 9.06, p>0.05$, Figure 3B).

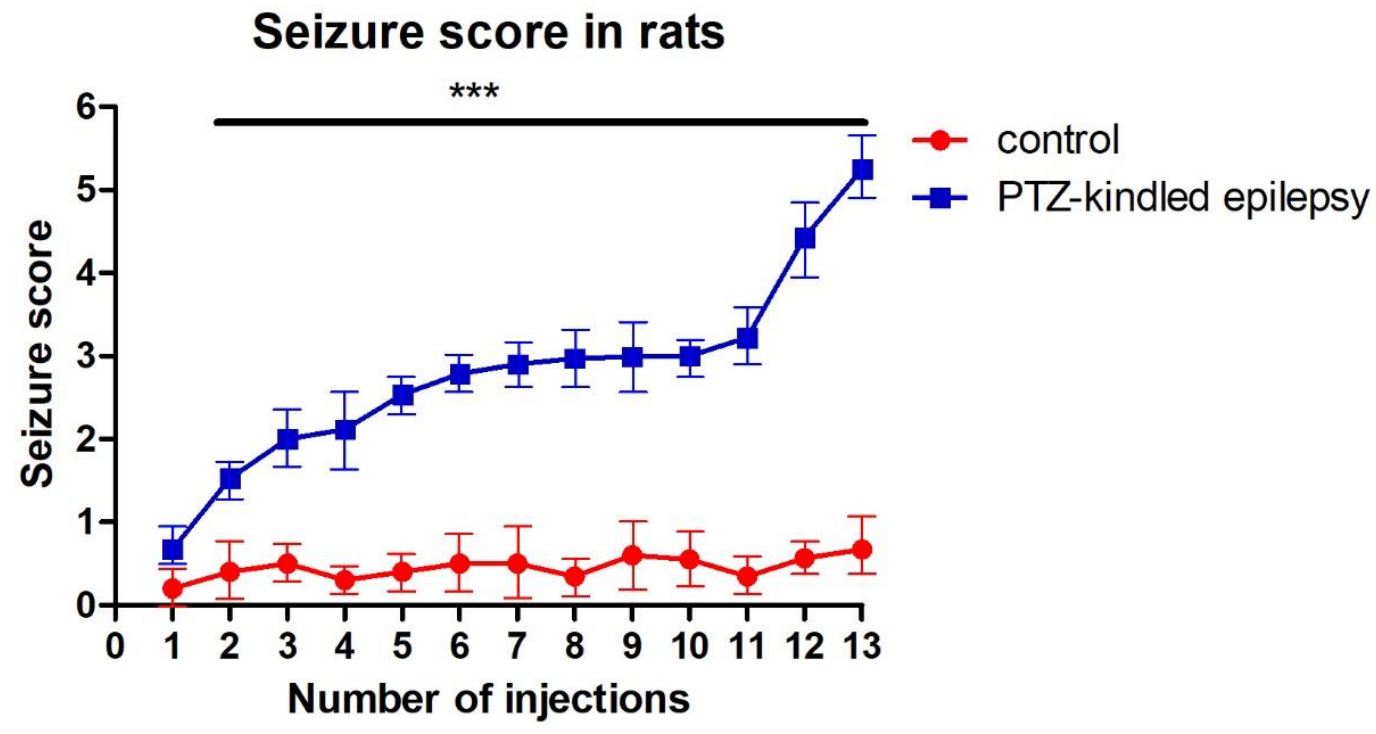

Figure 2. Racine score exhibited by sham control and PTZ-kindled epilepsy rats. Values are presented as the mean \pm SEM, $n=10$ for each group, ${ }^{* * *} p<0.001$.

A

Control

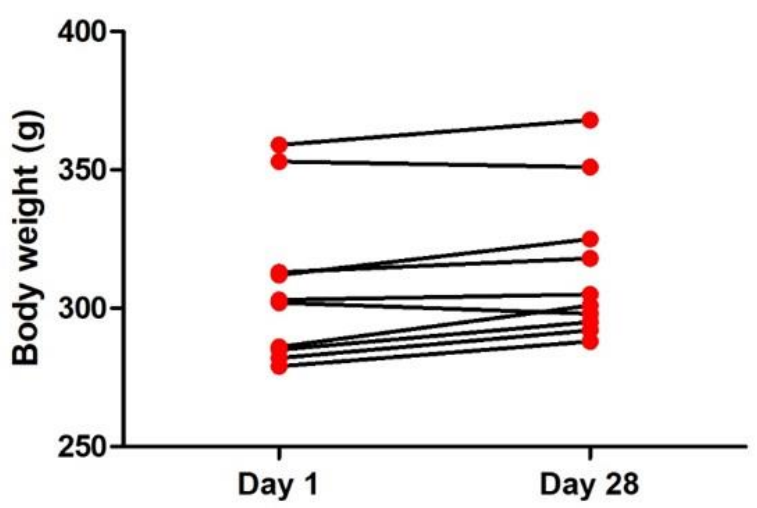

B

\section{PTZ-kindled epilepsy}

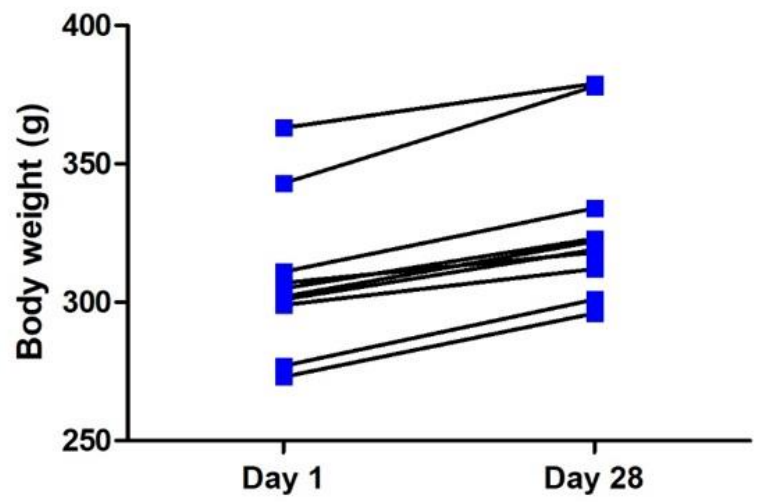

Figure 3. Body weight changes in control (A) and PTZ-kindled epilepsy (B) groups between day 1 and day 28 of treatment, $n=10$ for each group, $p>0.05$.

\subsection{Gross Histopathology Findings}

The H\&E-stained tissue images were assessed for gross histopathological changes in the cortex (Figure 4A,D), hippocampus (Figure 4B,E), and medulla (Figure 4C,F). Compared to controls, the PTZ-kindled animals (Group 2) showed increased observations of necrotic cortical cells, neuronal degeneration in the hippocampal cells, and haemorrhagic areas in the medulla oblongata. 


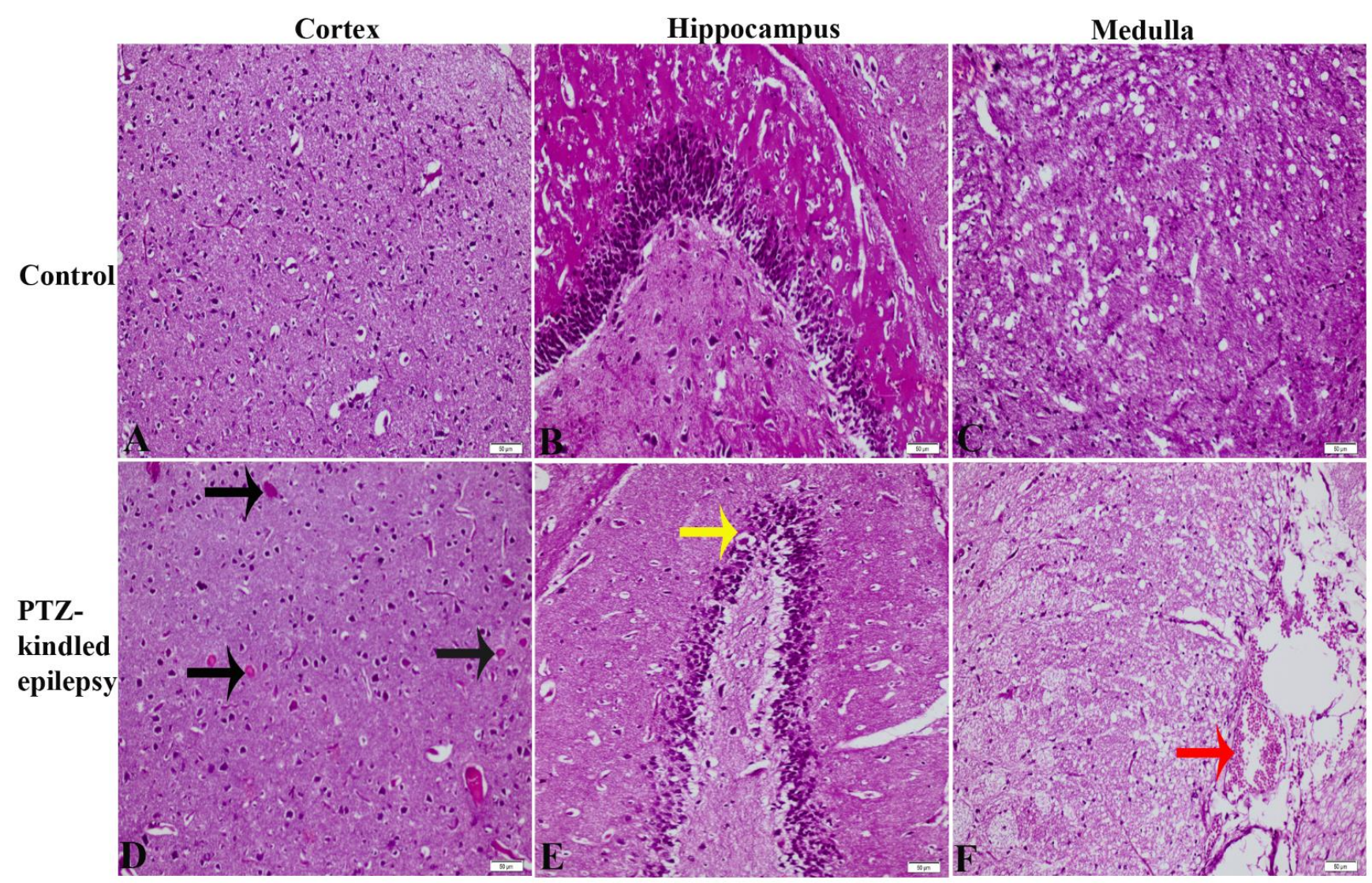

Figure 4. Haematoxylin and Eosin (H\&E) staining images of the brain (cortex, hippocampus, and medulla) sections stained with purple in control (A-C, respectively) and PTZ-kindled epilepsy (D-F, respectively) groups. The black, yellow, and red arrows denote necrotic cells, cell degeneration, and haemorrhagic areas, respectively. Magnification of $\times 200$. Scale bar: $50 \mu \mathrm{m}$.

\subsection{Immunohistochemistry Findings}

\subsubsection{Upregulation of the Muscarinic ACh Receptor M2}

Compared to the control group, the PTZ-kindled rats demonstrated significant upregulation of the M2 receptor immunoreactivity in the cortex and the medulla (Figure 5A,C,D,F, respectively). There were no observable/significant intergroup immunoreactivity changes of the M2 receptor in the hippocampus. The PTZ-kindled animals showed an increased M2 Ach receptor immunoreactivity: $86.17 \pm 1.32$ vs. $79.64 \pm 0.99$ in the cortex $(* * *<<0.001)$ and $76.56 \pm 0.73$ vs. $72.97 \pm 0.59$ in the medulla oblongata (** $p<0.01$ ) (Figure $5 \mathrm{G}$ ), when compared to the respective area in the control group. The M2 ACh receptor immunoreactivity in the PTZ-kindled hippocampus showed no significant difference with the control group (88.62 \pm 0.92 vs. $91.26 \pm 1.27, p>0.05$, Figures $3 \mathrm{E}$ and $5 \mathrm{~B})$. 

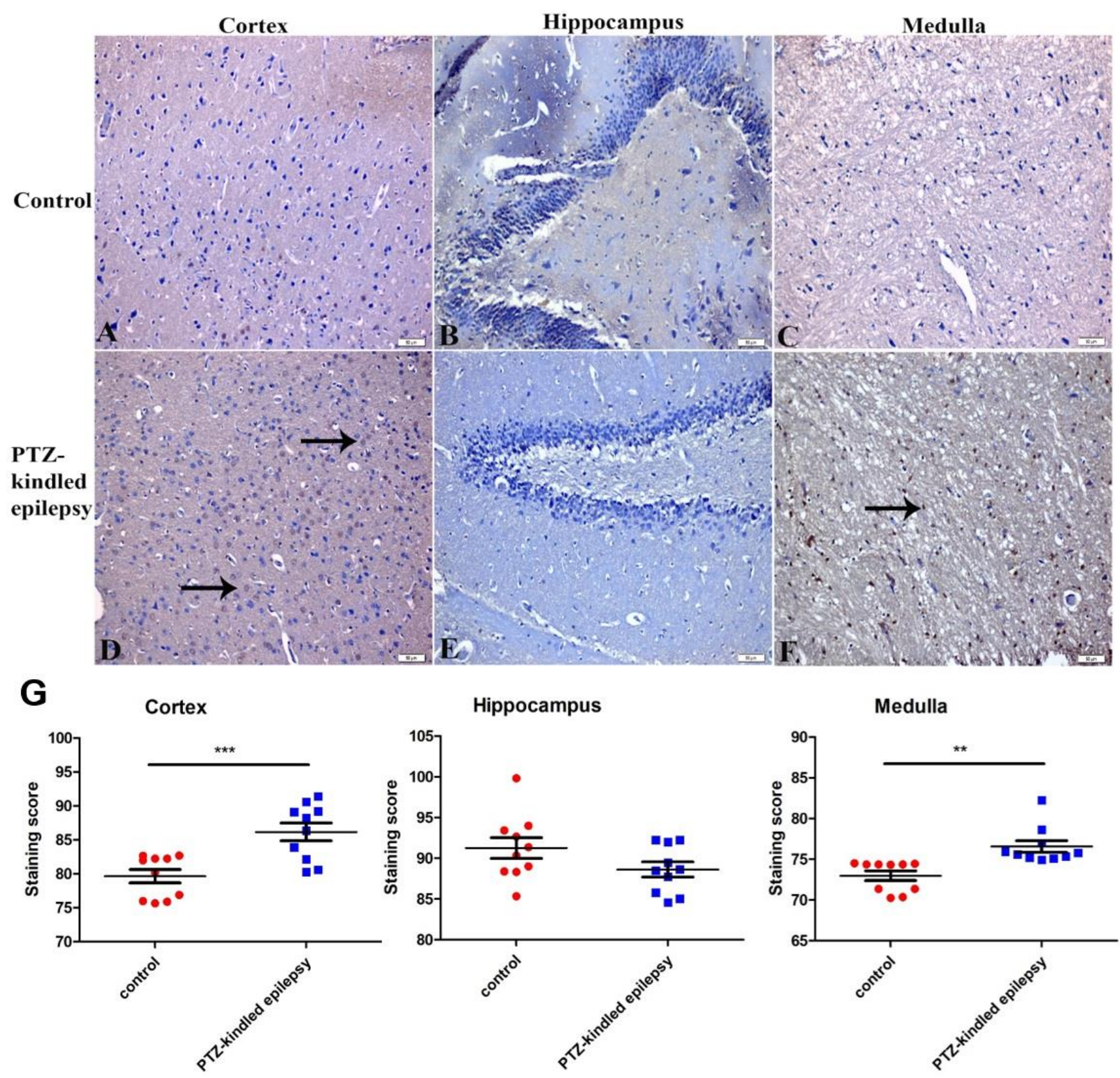

Figure 5. Representative images of M2 receptors within the cortex, hippocampus, and medulla in control (A-C, respectively) and PTZ-kindled epilepsy of rat model (D-F, respectively). Figure (G) represents the M2 ACh receptor's immunoreactivity in the cortex, medulla, and hippocampus regions. Values are presented as the mean $\pm \operatorname{SEM}, n=10$, ${ }^{* *} p<0.01$ and ${ }^{* * *} p<0.001$. The black arrow indicates the increased immunoreactive cells. Pictures were taken at a magnification of $\times 200$. Scale bar: $50 \mu \mathrm{m}$.

\subsubsection{Upregulation of the Serotonin Receptor 2B (5-HT2B)}

Upregulation of the 5-HT2B immunoreactivity was observed within the cortex, hippocampus, and medulla of the PTZ-kindled rats when compared to the control animals (Figure 6A-F). Compared to the control group, the serotonin receptor 2B immunoreactivity in the PTZ-kindled group was found to be increased in the cortex $(84.11 \pm 1.70 \mathrm{vs}$. $\left.79.91 \pm 0.94,{ }^{*} p<0.05\right)$ and in the medulla (83.26 \pm 0.71 vs. $\left.77.78 \pm 0.46,{ }^{* * *} p<0.001\right)$ (Figure 6G). However, the 5-HT2B immunoreactivity was found to be decreased in the hippocampus (91.87 \pm 1.26 vs. $\left.110.90 \pm 1.94,{ }^{* * *} p<0.001\right)$ of the PTZ-kindled group when compared to the control group (Figure 6G). 

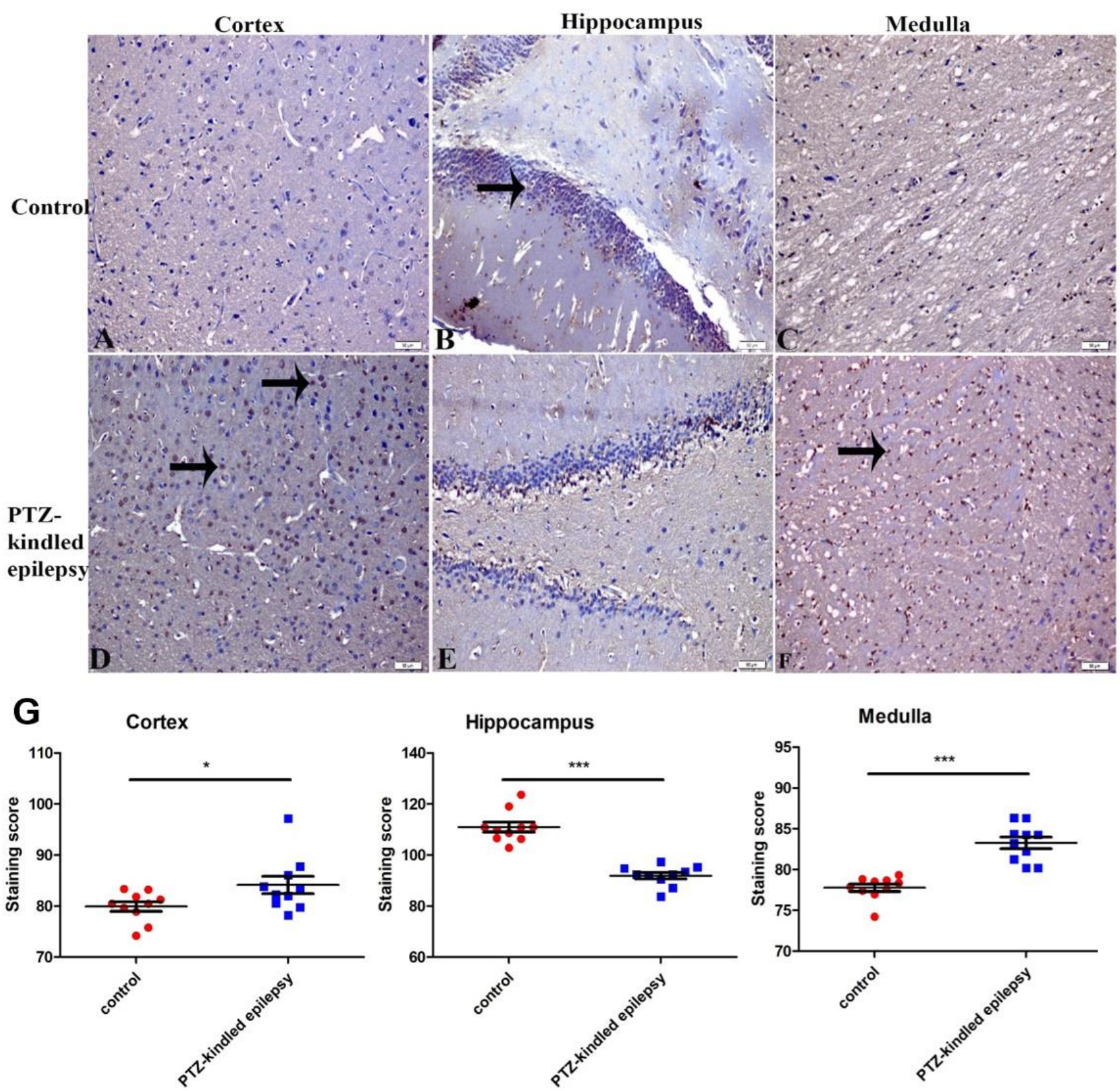

Figure 6. Representative images of immunoreactivity for serotonin receptors within the cortex, hippocampus, and medulla in control (A-C, respectively) and PTZ-kindled (D-F, respectively). Figure (G) represents the immunoreactivity of the serotonin receptor $2 \mathrm{~B}$ in several regions (cortex, medulla, and hippocampus). Values are presented as the mean $\pm \mathrm{SEM}$, $n=10,{ }^{*} p<0.05$, and ${ }^{* *} p<0.001$. The black arrow indicates the immunoreactive cells. Pictures were taken at a magnification of $\times 200$. Scale bar: $50 \mu \mathrm{m}$.

\subsubsection{Increased Immunoreactivity of Norepinephrine Transporter}

The upregulation of NE transporters was witnessed in all three PTZ-kindled brain regions, the cortex, hippocampus and medulla, when compared to the control group (Figure 7A-F). Similarly, the PTZ-kindled rats showed significantly increased immunoreactivity in the NE transporter in the cortex $(83.39 \pm 0.59$ vs. $80.32 \pm 0.89, * p<0.05)$, hippocampus $(94.92 \pm 0.66$ vs. $\left.89.53 \pm 0.53{ }^{* * *} p<0.001\right)$, and in the medulla $(80.83 \pm 0.54$ vs. $77.59 \pm 0.65, * * p<0.01)$, when compared to the respective brain regions in the control group (Figure 7G). 


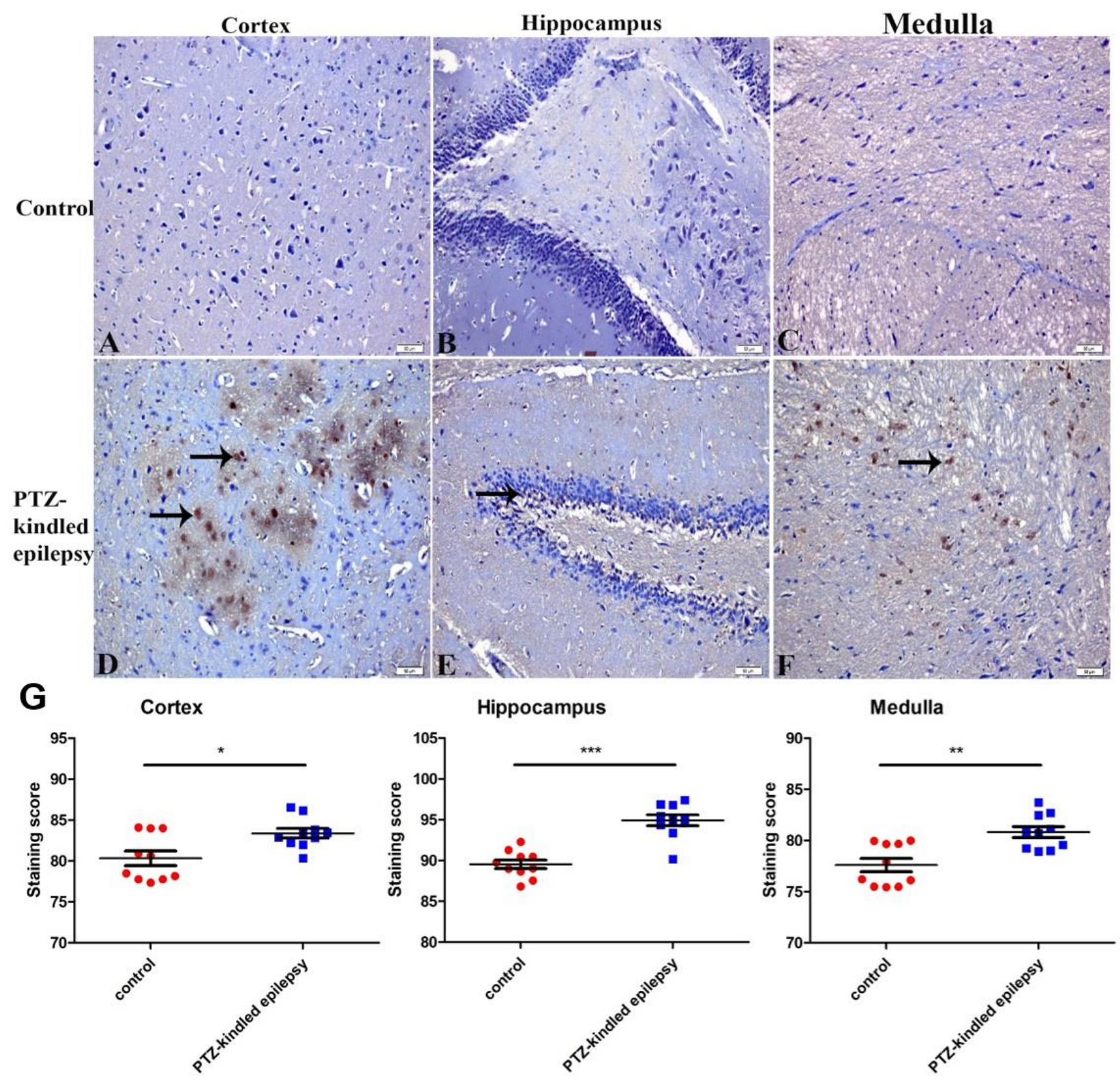

Figure 7. Representative images of immunoreactivity for NE transporter within the cortex, hippocampus, and medulla in control (A-C, respectively) and PTZ-kindled (D-F, respectively). Figure (G) represents the immunoreactivity of the NE transporter in several regions (cortex, medulla, and hippocampus). Values are presented as the mean $\pm \mathrm{SEM}, n=10$, ${ }^{*} p<0.05,{ }^{* *} p<0.01$ and ${ }^{* * *} p<0.001$. The black arrow indicates the increased immunoreactive cells. Pictures were taken at a magnification of $\times 200$. Scale bar: $50 \mu \mathrm{m}$.

\subsubsection{Ach-Activated Kir3.1 Channel and ATP-Dependent Kir6.2 Channel}

Immunohistological staining showed an increased immunoreactivity of Kir3.1 channels in the cortex and hippocampus (Figure 8A-F), while an increased immunoreactivity of the Kir6.2 channel was observed in the cortex and medulla (Figure 9A-F) of the PTZkindled animals when compared to the control rats. 


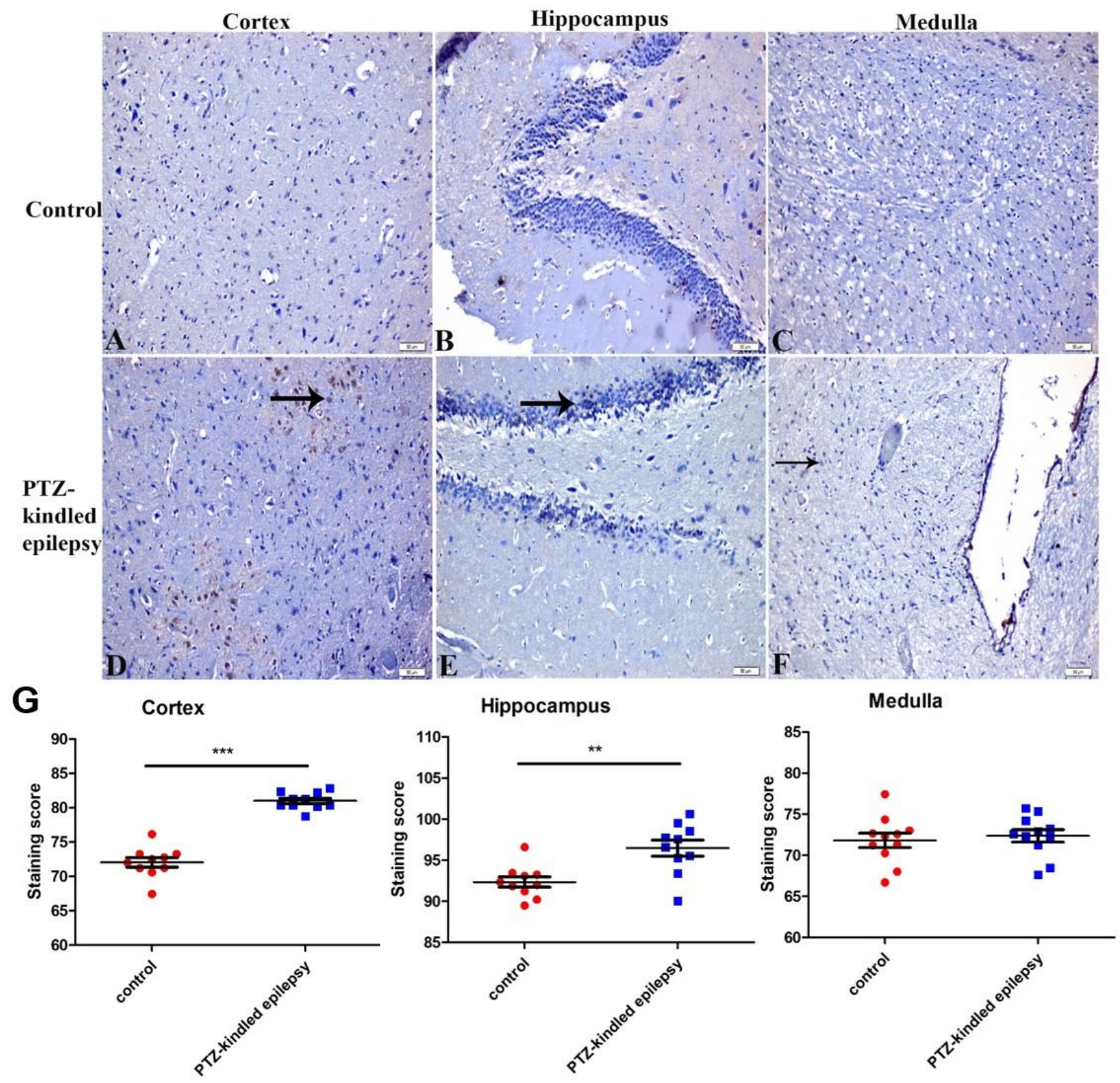

Figure 8. Representative images of immunoreactivity for Kir3.1 channel within the cortex, hippocampus, and medulla in control (A-C) and PTZ-kindled epilepsy of rat model (D-F), respectively. Figure (G) represents the immunoreactivity of the Kir3.1 channel in several regions (cortex, medulla, and hippocampus). Values are presented as the mean $\pm \mathrm{SEM}$, $n=10,{ }^{* *} p<0.01$ and ${ }^{* * *} p<0.001$. The black arrow indicates the changed immunoreactive cells. Pictures were taken at a magnification of $\times 200$. Scale bar: $50 \mu \mathrm{m}$. 


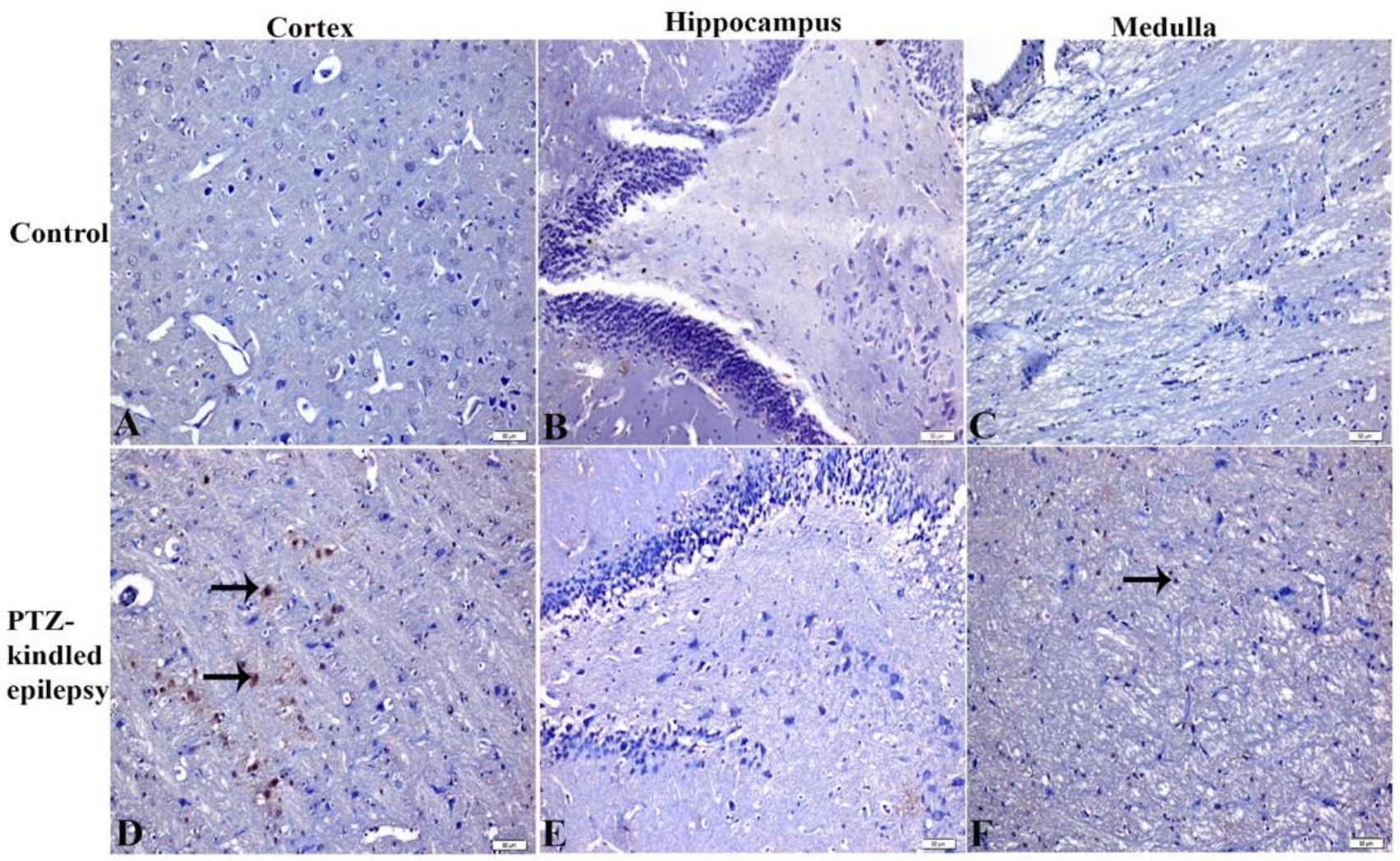

G

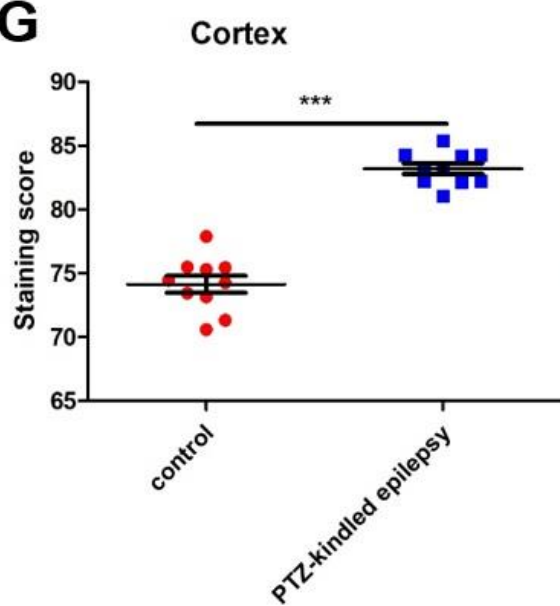

Hippocampus

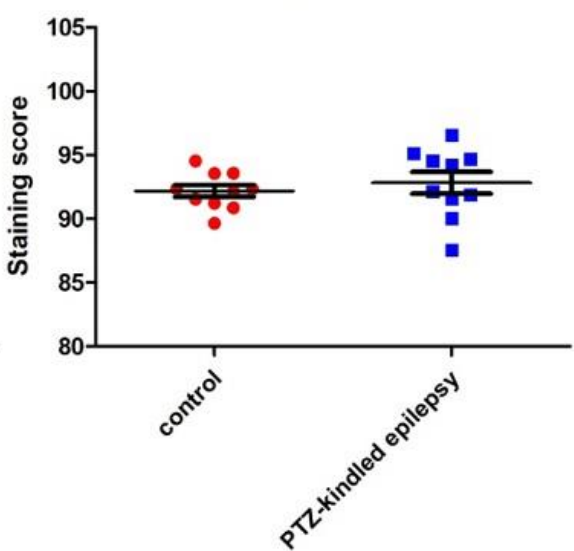

Medulla

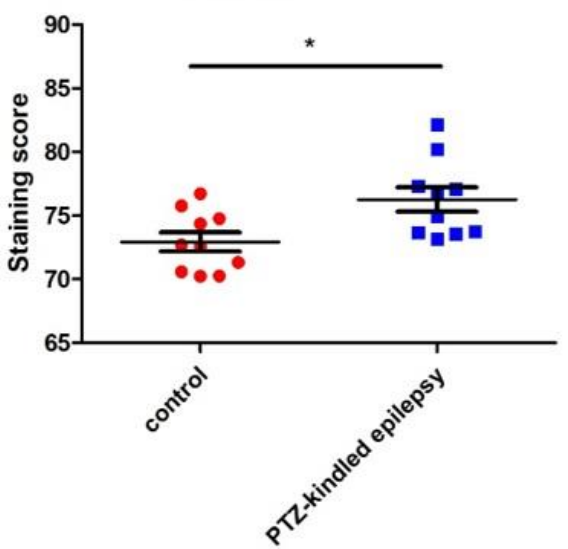

Figure 9. Representative images of immunoreactivity for Kir6.2 channel within the cortex, hippocampus, and medulla in control (A-C) and PTZ-kindled epilepsy of rat model (D-F), respectively. Figure (G) represents the immunoreactivity of the Kir6.2 channel in several regions (cortex, medulla, and hippocampus). Values are presented as the mean $\pm \operatorname{SEM}, n=10, * p$ $<0.05$ and ${ }^{* * *} p<0.001$. The black arrow indicates the changed immunoreactive cells. Pictures were taken at a magnification of $\times 200$. Scale bar: $50 \mu \mathrm{m}$.

In the PTZ-kindled group, an increased Kir3.1 immunoreactivity was observed in the cortex $\left(80.98 \pm 0.39\right.$ vs. $\left.720.4 \pm 0.71{ }^{* * *} p<0.001\right)$ and hippocampus $(96.47 \pm 0.98$ vs. $92.35 \pm 0.62,{ }^{* *} p<0.01$ ) when compared to the control animals, but there were no significant Kir3.1 immunoreactivity differences observed in the medulla between the two groups (72.36 \pm 0.76 vs. $71.81 \pm 0.88, p>0.05$, Figure $8 G$ ).

The PTZ-kindled group also had an increased immunoreactivity of Kir6.2 in the cortex $\left(83.20 \pm 0.42\right.$ vs. $\left.74.14 \pm 0.68{ }^{* * *} p<0.001\right)$ and the medulla $(76.26 \pm 0.97$ vs. $72.93 \pm 0.75$, $* p<0.05$ ), respectively, when compared with the control group (Figure 9G). No significant 
differences in Kir6.2 immunoreactivity were observed in the hippocampus of the PTZ-kindled animals when compared to the control group (92.82 \pm 0.86 vs. $92.18 \pm 0.46, p>0.05)$.

\section{Discussion}

The findings from our study demonstrated that chronic PTZ-kindling induces locationspecific alterations in the immunoreactivity of ion channels as well as of neurotransmitter receptors and transporters, which may play a role in ictogenesis. We found significantly increased immunoreactivity of the NE transporter, the M2 and 5-HT2B receptors as well as the Kir3.1 and Kir6.2 ion channels in the cortex of the PTZ-kindled rats when compared to the sham controls. As for the medulla, only the Kir3.1 ion channel did not show any significant upregulation when compared to sham controls. However, in the hippocampus, only the NE transporters and Kir3.1 channels showed increased immunoreactivity, but the 5-HT2B receptors showed a decrease in immunoreactivity, while the M2 receptors and Kir6.2 channels showed no significant changes in immunoreactivity when compared to controls. This supports the notion that different brain areas may have different pathological processes/roles in epilepsy and thus should be taken into consideration in future pathological studies. We believe that these kindling-induced changes in immunoreactivity may contribute to ictogenesis and even epileptogenesis, or may cause compensatory effects that will decrease excitability and result in epiphenomena. However, these speculations will require future studies to effectively assess the potential pathogenic/ictogenesis/epileptogenesis role of each of these immunoreactivity changes in a more counterintuitive way.

Neurotransmitters may excite, inhibit or modulate neuronal activity through receptors/transporters and ion channels, thereby potentially playing a crucial role in altering seizure threshold/activity and epileptogenesis. For example, mutations in the CHRNA4 gene, which encodes for the nicotinic ACh receptor subunit, may cause the development of nocturnal frontal lobe epilepsy [27], while pilocarpine, a nonselective muscarinic receptor agonist, may initiate seizures and status epilepticus in experimental animals [28]. Similarly, the 5-HT receptor has been shown to alter seizure thresholds in PTZ, kainic acid, and penicillin animal epilepsy models. The 5-HT1A receptor agonists have been observed to prolong the seizure latency and decrease the frequency of PTZ-induced tonic-clonic convulsions as well as of kainic acid-induced status epilepticus [29]. As with the 5-HT1A receptor, the 5-HT2 receptor agonists have also been suggested to reduce epileptiform activity in a penicillin epilepsy model, which was found to be counteracted (increased epileptiform activity) with a 5-HT2 receptor antagonist treatment, methysergide [30]. Hence, in our study, the increased expression but decreased immunoreactivity (inhibition) of the 5-HT2B receptors in the hippocampus may contribute to the epileptogenesis process, while the increased immunoreactivity of the receptor in the cortex and medulla may indicate a more neuroprotective role of serotonin against seizures. Seizure-related increases in serum 5-HT levels are associated with a lower incidence of respiratory dysfunction (role of medulla), which may provide a protective effect against sudden unexpected death in epilepsy (SUDEP) [31]. However, in surgical tissues from TLE patients, low hippocampal serotonin levels were significantly correlated with a history of generalized tonic-clonic seizures [32]. Thus, our results support that the seizure threshold may be reduced due to decreased hippocampal 5-HT2B receptor immunoreactivity, but further behavioural/functional outcomes should be performed to determine if the increases in the cortex and medulla may provide protection against the seizure kindling as well.

Interestingly, transgenic mice lacking the 5-HT1A or 5-HT2C receptors tend to develop epilepsy, with an increased seizure frequency that was associated with a decrease in 5-HT and NE levels [33]. Decreased NE levels are related to the increased expression of the norepinephrine transporter (NET), an inverse relationship. The NET removes NE from the synapse of noradrenergic neurons and also plays a role in dopamine reuptake in the hippocampus and cortex [34]. Norepinephrine has anti-seizure and antiepileptic effects in animal models [35], thus a decrease in NE may result in ictogenesis and epileptogenesis [36]. In our PTZ-kindled model, the NET immunoreactivity was upregulated 
in the hippocampus, medulla, and cortex, suggesting a possible decrease in NE levels which therefore may propagate epileptogenesis. Since the neurotransmitter levels were not investigated in this study, whether the epileptogenesis pathway was initiated by either the decrease in NE or the decrease in dopamine levels remains to be determined.

As for the Kir ion channels, Kir6.2 channel immunoreactivity has been shown to be increased after seizures in a cellular epilepsy model established by culturing hippocampal neurons in a magnesium-free medium [37]. Similarly, the seizure threshold was seen to be decreased in a mice model with genetically down-regulated Kir6.2 channels [38]. On the other hand, Kir3 channels may exhibit a duality in epileptogenesis; pro-convulsant or anti-convulsant effect. Studies show that inhibiting Kir3 channels results in seizure development and activating Kir3 channels may prevent epileptogenesis, but kindled seizures may increase the immunoreactivity of Kir3 channels as a compensatory mechanism towards neuroprotection against excessive stimulation [39]. Thus, the increased immunoreactivity of Kir3.1 channels in our study may suggest a neuroprotective role against the kindled seizures, but further studies are needed to determine if the increased immunoreactivity propagates epileptogenesis thereafter. The opposite may be true for the increased immunoreactivity of the Kir6.2 channels, as they may result in increased seizure activity instead.

Epilepsy/seizures may affect the autonomic nervous system, resulting in cardiac and respiratory dysfunctions, a precursor towards SUDEP [40]. Studies have shown that the 5-HT transport may be impaired in the ventrolateral medulla (VLM) and medullar raphe (MR) regions, which are involved in respiratory control in SUDEP conditions [41]. Moreover, lesions in 5-HT neurons projecting to respiratory nuclei may impair autonomic function by suppressing respiration after seizures [42]. Using functional imaging, receptor immunoreactivity changes were also found in the connections between the autonomic regulatory cortex regions and the brainstem [43]. This, taken together with the loss/lesion of serotonergic neurons and specialized glial cells in VLM and medullary raphe (MR), may cause impairment in the responsiveness of respiratory neurons during or after seizures [44], thereby contributing to the SUDEP risk. In addition, the opening of the Kir6.2 channels in the brainstem neurons may synchronize with the respiratory firing rhythm [45]. In our study, we found increased expression of the medullar Kir6.2 channels after PTZ-kindling, suggesting the possible desynchronization (rapid firing) of the respiratory system, which unfortunately was not investigated but may be warranted in future studies. Besides that, increased medullary M2 receptor immunoreactivity, similar to our study, may also contribute to the impairment in cardiorespiratory regulation, especially when in combination with Kir3.1 upregulation [26]. Future studies should perform ion-current measurements of the Kir channels in association with the immunoreactivity changes of M2 receptors in the medulla in order to better understand the underlying mechanisms relating epilepsy to cardiorespiratory dysfunctions.

This study also observed gross pathological changes; necrosis in the cortex, cellular degeneration in the hippocampus and haemorrhage in the medulla, in the PTZ-kindled rats compared to the controls. Seizures may increase heart rate, blood pressure, neuronal metabolism, and cerebral blood flow, which may result in brain damage due to adenosine triphosphate (ATP) depletion and lactate accumulation caused by hypermetabolic neural necrosis [46]. Hippocampal damage and reduced glucose metabolism have also been reported previously after PTZ-induced seizures, where they were associated with increased oxidative stress found in the hippocampus as well as in the cerebral cortex [47]. In the PTZkindling model, severe necrosis and degeneration with vacuolization were also observed in the hippocampal neurons in a past study [48]. On the contrary, this pathology in our model may have also been observed due to the final overdose (50 mg/ $\mathrm{kg}$, i.p.) of PTZ in the animals, resulting in severe neurotoxic pathology in the brain. 


\section{Conclusions}

In conclusion, chronic/long-term PTZ-kindling was associated with increased immunoreactivity of neurotransmitter receptors/transporters and ion channels, which may govern the neurotransmitter levels such as ACh, serotonin, and NE in the cortex, hippocampus, and medulla. Although these changes may have resulted from seizure kindling, they may also contribute to the molecular pathogenesis of epilepsy in the long run. Our findings suggest that alternative therapeutic approaches may target these neurotransmitter receptors/transporters, as well as the alterations in Kir channel function, to treat epilepsy, especially drug-resistant epilepsy, and prevent epilepsy related autonomic comorbidities such as SUDEP, thereby improving the future lives of epileptic patients.

Author Contributions: E.A. conceived the experiment and drafted the manuscript. E.A., Z.D., B.K. and E.K. conducted the entire experiment, from behaviour to molecular work and analysis. Y.N.P. and C.V. commented on the figures, visualized and investigated the manuscript. A.A., M.F.S. and O.D. provided critical inputs, revised, and extensively edited the final version of the manuscript. All authors have read and agreed to the published version of the manuscript.

Funding: This study was supported by the grant from Yozgat Bozok University, Scientific Research Unit (project grant number: 6602c-TF/19-299).

Institutional Review Board Statement: The study was conducted according to the guidelines of the Declaration of Helsinki, and approved by the Animal Ethics Committee of the Kayseri Erciyes University (numbered: 19/027).

Informed Consent Statement: Not applicable.

Data Availability Statement: Not applicable.

Acknowledgments: The authors would like to thank Yozgat Bozok University for the generous support in terms of experimental and laboratory facilities.

Conflicts of Interest: The authors declare that they have no competing interests.

\section{References}

1. Thijs, R.D.; Surges, R.; O’Brien, T.J.; Sander, J.W. Epilepsy in adults. Lancet 2019, 393, 689-701. [CrossRef]

2. Vossler, D.G.; Weingarten, M.; Gidal, B.E.; American Epilepsy Society Treatments Committee. Summary of Antiepileptic Drugs Available in the United States of America: WORKING TOWARD A WORLD WITHOUT EPILEPSY. Epilepsy Curr. 2018, 18, 1-26. [CrossRef] [PubMed]

3. Kwan, P.; Brodie, M.J. Early identification of refractory epilepsy. N. Engl. J. Med. 2000, 342, 314-319. [CrossRef]

4. Devinsky, O.; Vezzani, A.; O’Brien, T.J.; Jette, N.; Scheffer, I.E.; de Curtis, M.; Perucca, P. Epilepsy. Nat. Rev. Dis Primers 2018, 4, 18024. [CrossRef] [PubMed]

5. Dalic, L.; Cook, M.J. Managing drug-resistant epilepsy: Challenges and solutions. Neuropsychiatr. Dis. Treat. 2016, 12, 2605-2616. [CrossRef] [PubMed]

6. Fukata, Y.; Fukata, M. Epilepsy and synaptic proteins. Curr. Opin. Neurobiol. 2017, 45, 1-8. [CrossRef] [PubMed]

7. Svob Strac, D.; Pivac, N.; Smolders, I.J.; Fogel, W.A.; De Deurwaerdere, P.; Di Giovanni, G. Monoaminergic mechanisms in epilepsy may offer innovative therapeutic opportunity for monoaminergic multi-target drugs. Front. Neurosci. 2016, 10, 492. [CrossRef]

8. Lascano, A.M.; Korff, C.M.; Picard, F. Seizures and epilepsies due to channelopathies and neurotransmitter receptor dysfunction: A parallel between genetic and immune aspects. Mol. Syndromol. 2016, 7, 197-209. [CrossRef] [PubMed]

9. Sonnewald, U.; Schousboe, A. Glutamate/Gaba-Glutamine Cycle; Springer: Cham, Switzerland, 2016.

10. Deransart, C.; Riban, V.; Le, B.; Marescaux, C.; Depaulis, A. Dopamine in the striatum modulates seizures in a genetic model of absence epilepsy in the rat. Neuroscience 2000, 100, 335-344. [CrossRef]

11. Celada, P.; Puig, M.V.; Artigas, F. Serotonin modulation of cortical neurons and networks. Front. Integr. Neurosci. 2013, 7, 25. [CrossRef]

12. Upton, N.; Stean, T.; Middlemiss, D.; Blackburn, T.; Kennett, G. Studies on the role of 5-HT2C and 5-HT2B receptors in regulating generalised seizure threshold in rodents. Eur. J. Pharmacol. 1998, 359, 33-40. [CrossRef]

13. Tolete, P.; Knupp, K.; Karlovich, M.; DeCarlo, E.; Bluvstein, J.; Conway, E.; Friedman, D.; Dugan, P.; Devinsky, O. Lorcaserin therapy for severe epilepsy of childhood onset: A case series. Neurology 2018, 91, 837-839. [CrossRef]

14. Kim, D. Modulation of acetylcholine-activated K+ channel function in rat atrial cells by phosphorylation. J. Physiol. 1991, 437, 133-155. [CrossRef] 
15. Ohno, Y.; Hibino, H.; Lossin, C.; Inanobe, A.; Kurachi, Y. Inhibition of astroglial Kir4.1 channels by selective serotonin reuptake inhibitors. Brain Res. 2007, 1178, 44-51. [CrossRef] [PubMed]

16. Ten Eick, R.; Nawrath, H.; McDonald, T.F.; Trautwein, W. On the mechanism of the negative inotropic effect of acetylcholine. Pflugers Arch. 1976, 361, 207-213. [CrossRef] [PubMed]

17. Wiser, O.; Qian, X.; Ehlers, M.; Ja, W.W.; Roberts, R.W.; Reuveny, E.; Jan, Y.N.; Jan, L.Y. Modulation of basal and receptor-induced GIRK potassium channel activity and neuronal excitability by the mammalian PINS homolog LGN. Neuron 2006, 50, 561-573. [CrossRef]

18. Downes, G.B.; Granato, M. Acetylcholinesterase function is dispensable for sensory neurite growth but is critical for neuromuscular synapse stability. Dev. Biol. 2004, 270, 232-245. [CrossRef]

19. Sun, H.S.; Feng, Z.P. Neuroprotective role of ATP-sensitive potassium channels in cerebral ischemia. Acta Pharmacol. Sin. 2013, 34, 24-32. [CrossRef] [PubMed]

20. Shi, X.R.; Chang, J.; Ding, J.H.; Fan, Y.; Sun, X.L.; Hu, G. Kir6.2 knockout alters neurotransmitter release in mouse striatum: An in vivo microdialysis study. Neurosci. Lett. 2008, 439, 230-234. [CrossRef] [PubMed]

21. Mueller, S.G.; Bateman, L.M.; Laxer, K.D. Evidence for brainstem network disruption in temporal lobe epilepsy and sudden unexplained death in epilepsy. Neuroimage Clin. 2014, 5, 208-216. [CrossRef]

22. Hattiangady, B.; Shetty, A.K. Implications of decreased hippocampal neurogenesis in chronic temporal lobe epilepsy. Epilepsia 2008, 49 (Suppl. 5), 26-41. [CrossRef] [PubMed]

23. Racine, R.J. Modification of seizure activity by electrical stimulation. II. Motor seizure. Electroencephalogr. Clin. Neurophysiol. 1972, 32, 281-294. [CrossRef]

24. Akyuz, E.; Polat, K.; Ates, S.; Unalmis, D.; Tokpinar, A.; Yilmaz, S.; Kaymak, E.; Doganyigit, Z.; Villa, C. Investigating Cardiac Morphological Alterations in a Pentylenetetrazol-Kindling Model of Epilepsy. Diagnostics 2020, 10, 388. [CrossRef]

25. Popova, I.; Malkov, A.; Ivanov, A.I.; Samokhina, E.; Buldakova, S.; Gubkina, O.; Osypov, A.; Muhammadiev, R.S.; Zilberter, T.; Molchanov, M.; et al. Metabolic correction by pyruvate halts acquired epilepsy in multiple rodent models. Neurobiol. Dis. 2017, 106, 244-254. [CrossRef]

26. Akyuz, E.; Doganyigit, Z.; Paudel, Y.N.; Kaymak, E.; Yilmaz, S.; Uner, A.; Shaikh, M.F. Increased ACh-Associated Immunoreactivity in Autonomic Centers in PTZ Kindling Model of Epilepsy. Biomedicines 2020, 8, 113. [CrossRef] [PubMed]

27. Becchetti, A.; Aracri, P.; Meneghini, S.; Brusco, S.; Amadeo, A. The role of nicotinic acetylcholine receptors in autosomal dominant nocturnal frontal lobe epilepsy. Front. Physiol. 2015, 6, 22. [CrossRef]

28. Nirwan, N.; Vyas, P.; Vohora, D. Animal models of status epilepticus and temporal lobe epilepsy: A narrative review. Rev. Neurosci. 2018, 29, 757-770. [CrossRef]

29. López-Meraz, M.-L.; González-Trujano, M.-E.; Neri-Bazán, L.; Hong, E.; Rocha, L.L. 5-HT1A receptor agonists modify epileptic seizures in three experimental models in rats. Neuropharmacology 2005, 49, 367-375. [CrossRef] [PubMed]

30. Taskiran, M.; Tasdemir, A.; Ayyildiz, N.; Ayyildiz, M.; Agar, E. The effect of serotonin on penicillin-induced epileptiform activity. Int. J. Neurosci. 2019, 129, 687-697. [CrossRef]

31. Murugesan, A.; Rani, M.R.S.; Vilella, L.; Lacuey, N.; Hampson, J.P.; Faingold, C.L.; Friedman, D.; Devinsky, O.; Sainju, R.K.; Schuele, S.; et al. Postictal serotonin levels are associated with peri-ictal apnea. Neurology 2019, 93, e1485-e1494. [CrossRef] [PubMed]

32. da Fonseca, N.C.; Joaquim, H.P.; Talib, L.L.; de Vincentiis, S.; Gattaz, W.F.; Valente, K.D. Hippocampal serotonin depletion is related to the presence of generalized tonic-clonic seizures, but not to psychiatric disorders in patients with temporal lobe epilepsy. Epilepsy Res. 2015, 111, 18-25. [CrossRef]

33. Venzi, M.; David, F.; Bellet, J.; Cavaccini, A.; Bombardi, C.; Crunelli, V.; Di Giovanni, G. Role for serotonin2A (5-HT2A) and 2C (5-HT2C) receptors in experimental absence seizures. Neuropharmacology 2016, 108, 292-304. [CrossRef]

34. Goral, I.; Latka, K.; Bajda, M. Structure Modeling of the Norepinephrine Transporter. Biomolecules 2020, 10, 102. [CrossRef] [PubMed]

35. Giorgi, F.S.; Pizzanelli, C.; Biagioni, F.; Murri, L.; Fornai, F. The role of norepinephrine in epilepsy: From the bench to the bedside. Neurosci. Biobehav. Rev. 2004, 28, 507-524. [CrossRef]

36. Ranjbar-Slamloo, Y.; Fazlali, Z. Dopamine and Noradrenaline in the Brain; Overlapping or Dissociate Functions? Front. Mol. Neurosci. 2019, 12, 334. [CrossRef] [PubMed]

37. Fu, Q.; Sun, Z.; Zhang, J.; Gao, N.; Qi, F.; Che, F.; Ma, G. Diazoxide preconditioning antagonizes cytotoxicity induced by epileptic seizures. Neural Regen. Res. 2013, 8, 1000-1006.

38. Yamada, K.; Ji, J.J.; Yuan, H.; Miki, T.; Sato, S.; Horimoto, N.; Shimizu, T.; Seino, S.; Inagaki, N. Protective role of ATP-sensitive potassium channels in hypoxia-induced generalized seizure. Science 2001, 292, 1543-1546. [CrossRef]

39. D'Adamo, M.C.; Catacuzzeno, L.; Di Giovanni, G.; Franciolini, F.; Pessia, M. K(+) channelepsy: Progress in the neurobiology of potassium channels and epilepsy. Front. Cell. Neurosci. 2013, 7, 134. [CrossRef] [PubMed]

40. Barot, N.; Nei, M. Autonomic aspects of sudden unexpected death in epilepsy (SUDEP). Clin. Auton. Res. 2019, 29, 151-160. [CrossRef]

41. Patodia, S.; Somani, A.; O’Hare, M.; Venkateswaran, R.; Liu, J.; Michalak, Z.; Ellis, M.; Scheffer, I.E.; Diehl, B.; Sisodiya, S.M.; et al The ventrolateral medulla and medullary raphe in sudden unexpected death in epilepsy. Brain 2018, 141, 1719-1733. [CrossRef] [PubMed] 
42. Richerson, G.B.; Buchanan, G.F. The serotonin axis: Shared mechanisms in seizures, depression, and SUDEP. Epilepsia 2011, 52 (Suppl. 1), 28-38. [CrossRef]

43. Allen, L.A.; Harper, R.M.; Lhatoo, S.; Lemieux, L.; Diehl, B. Neuroimaging of Sudden Unexpected Death in Epilepsy (SUDEP): Insights From Structural and Resting-State Functional MRI Studies. Front. Neurol. 2019, 10, 185. [CrossRef] [PubMed]

44. Patodia, S.; Paradiso, B.; Ellis, M.; Somani, A.; Sisodiya, S.M.; Devinsky, O.; Thom, M. Characterisation of medullary astrocytic populations in respiratory nuclei and alterations in sudden unexpected death in epilepsy. Epilepsy Res. 2019, 157, 106213. [CrossRef] [PubMed]

45. Haller, M.; Mironov, S.L.; Karschin, A.; Richter, D.W. Dynamic activation of K(ATP) channels in rhythmically active neurons. J. Physiol. 2001, 537, 69-81. [CrossRef] [PubMed]

46. Donaire, A.; Carreno, M.; Gomez, B.; Fossas, P.; Bargallo, N.; Agudo, R.; Falip, M.; Setoain, X.; Boget, T.; Raspall, T.; et al. Cortical laminar necrosis related to prolonged focal status epilepticus. J. Neurol. Neurosurg. Psychiatry 2006, 77, 104-106. [CrossRef]

47. Samokhina, E.; Samokhin, A. Neuropathological profile of the pentylenetetrazol (PTZ) kindling model. Int. J. Neurosci. 2018, 128, 1086-1096. [CrossRef]

48. Ali, S.O.; Shahin, N.N.; Safar, M.M.; Rizk, S.M. Therapeutic potential of endothelial progenitor cells in a rat model of epilepsy: Role of autophagy. J. Adv. Res. 2019, 18, 101-112. [CrossRef] [PubMed] 